\title{
Treatment of congenital hypothyroidism in a newborn with malabsorption after subtotal ileum resection
}

\author{
Charlotte S Schömig', Marie-Ėve Robinson² and Julia E von Oettingen² \\ 1Department of Pediatrics, University of Cologne, Cologne, Germany and 2Division of Endocrinology, \\ Department of Pediatrics, McGill University Health Center, Montreal, Canada
}

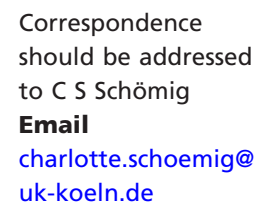

\section{Summary}

Congenital hypothyroidism requires prompt treatment to prevent adverse health outcomes. Poor intestinal levothyroxine absorption can complicate management. We present a case of a term female newborn with necrotizing enterocolitis (NEC) requiring subtotal ileum resection. Congenital hypothyroidism was diagnosed by newborn screening. Treatment was complicated by intestinal malabsorption of levothyroxine. Intravenous levothyroxine substitution restored euthyroidism and supraphysiologic PO doses subsequently maintained a euthyroid state. After several months, the required levothyroxine dose was weaned down to typical recommended dosing. In conclusion, small bowel resection secondary to NEC may lead to malabsorption of oral levothyroxine. An intravenous levothyroxine dose of approximately $50 \%$ typical PO dosing is effective in providing rapid normalization of free T4 and TSH. High PO doses may be required to maintain euthyroidism. Close thyroid function monitoring and immediate therapy adjustment are essential as the individual absorption may vary widely. Normal absorption levels may be regained due to adaption of the neonatal intestines.

\section{Learning points:}

- In neonates with malabsorption after ileum resection intravenous levothyroxine replacement should be used to provide normalization of free T4 and TSH.

- Very high doses of up to $500 \%$ usual oral levothyroxine may be required to maintain euthyroidism. The estimated degree of malabsorption can be used to determine the initial dose.

- Close thyroid function monitoring and immediate therapy adjustment are essential as the absorption and intestinal adaption may vary widely.

\section{Background}

Congenital hypothyroidism $(\mathrm{CH})$ is the most common congenital disorder of the endocrine system (1). Immediate levothyroxine (L-T4) substitution is indicated upon diagnosis to prevent possible severe complications, including neurocognitive sequelae. Necrotizing enterocolitis (NEC) can result from undiagnosed severe $\mathrm{CH}(2,3)$ and may necessitate extensive bowel resection. While absorption of enterally administered L-T4 is known to mainly occur in the jejunoileal area, several factors can influence absorption levels, thereby complicating treatment (4). Little has been reported on optimal L-T4 replacement strategies in neonates requiring bowel resection following NEC.

We present a case of a newborn with $\mathrm{CH}$ and NEC, whose reduced intestinal absorption capacity after subtotal ileum resection challenged management of $\mathrm{CH}$. 


\section{Case presentation}

The female infant was born at $39+4$ weeks gestation by cesarean section due to failure to progress. The pregnancy was complicated by diet-controlled gestational diabetes. At birth, the patient showed respiratory distress requiring intubation. APGAR scores were 9,2 and 8 at 1,5 and $10 \mathrm{~min}$ respectively. Umbilical cord $\mathrm{pH}$ was 7.36 . No hypoglycemic events were documented. A complete blood count was reported as normal. Birth weight was $3190 \mathrm{~g}$. A chest X-ray showed findings consistent with respiratory distress syndrome (RDS). The patient received two doses of surfactant and was extubated the following day. Initially nil PO while receiving 10\% dextrose containing IV fluids at $65 \mathrm{cc} / \mathrm{kg} /$ day, and gavage feeds were started the next day. She subsequently had difficulty feeding and presented bradycardia during feeds. The neurological examination revealed increased axial and appendicular tone, while EEG showed no pathologies.

On day 8, the patient presented with blood per rectum and abdominal distension. An X-ray showed pneumatosis intestinalis and portal venous air. Oral feedings were stopped and antibiotic treatment with ampicillin and gentamicin was started, but the distension progressed and emesis occurred. The following day, the patient presented with respiratory and hemodynamic deterioration requiring re-intubation, hemodynamic support with dopamine and hydrocortisone, and emergency transfer to a level four neonatal intensive care unit. A cortisol level prior to initiating hydrocortisone for hemodynamic support was $2165 \mathrm{nmol} / \mathrm{L}$ (normal range $120-620 \mathrm{nmol} / \mathrm{L})$. Antibiotic therapy was broadened to piperacillin, tazobactam and tobramycin. On admission, exploratory laparotomy was performed and revealed $60 \mathrm{~cm}$ ileum necrosis, which was resected. Approximately $85 \mathrm{~cm}$ of the small bowel distal to the ligament of Treitz as well as the ileocecal valve and $1-2 \mathrm{~cm}$ of proximal small bowel were kept intact, but initially left out of continuity. Additionally, a small perforation of the appendix was found and appendectomy was performed. Pathological examination of the resected necrotic ileum confirmed severe bowel necrosis secondary to NEC. Reanastomosis was performed 3 days later. The patient developed cholestasis (Table 1).

\section{Investigation}

On day 12, newborn screening, which in Quebec, Canada includes a TSH drawn after $24 \mathrm{~h}$ of life, revealed an elevated thyroid-stimulating hormone (TSH) concentration of $233.1 \mathrm{IU} / \mathrm{L}$ (normal range $<10 \mathrm{IU} / \mathrm{L}$ ) and reduced total T4 level of $37.76 \mathrm{nmol} / \mathrm{L}$ (normal range: $>120 \mathrm{nmol} / \mathrm{L}$ ). Upon re-examination in serum the same day, TSH was $97.84 \mathrm{IU} / \mathrm{L}$ (normal range: $0.34-5.6 \mathrm{IUL}$ ) and free $\mathrm{T} 42.8 \mathrm{pmol} / \mathrm{L}$ (normal range newborns: $12-55 \mathrm{pmol} / \mathrm{L}$, non-newborns: $8-18 \mathrm{pmol} / \mathrm{L}$ ). Subsequent TSH and free T4 values are shown in Fig. 1. Anti-thyroid peroxidase antibodies were $<0.35 \mathrm{IU} / \mathrm{mL}$ (normal range $0-9 \mathrm{IU} / \mathrm{mL}$ ).

\section{Treatment}

Treatment with intravenous LT-4 was immediately started at $5 \mu \mathrm{g} / \mathrm{kg} /$ day $(\sim 30 \%$ of a usual neonatal PO starting dose of $15 \mu \mathrm{g} / \mathrm{kg} /$ day), since patient was fed solely parenterally. Due to the continuously increasing TSH $(>100 \mathrm{IU} / \mathrm{L}$ on day 14), the daily dose was increased to $6.3 \mu \mathrm{g} / \mathrm{kg} /$ day ( $40 \%$ of a usual neonatal PO starting dose), leading to a significant decrease in TSH to $45.25 \mathrm{IU} / \mathrm{L}$ over a period of 11 days (Fig. 1).

Trophic feeds were started one week after the patient's bowel resection. After obtaining appropriate feeding tolerance, intravenous L-T4 was discontinued and oral L-T4 in the form of crushed tablets at $13.8 \mu \mathrm{g} / \mathrm{kg} /$ day was started on day 25. TSH levels two weeks later had risen to $>100 \mathrm{IU} / \mathrm{L}$ with a free T4 of $9.9 \mathrm{pmol} / \mathrm{L}$. Poor intestinal absorption being the likely culprit, treatment was switched back to intravenous L-T4 $(6.4 \mu \mathrm{g} / \mathrm{kg} / \mathrm{day})$. Different

Table 1 Cholestasis parameters.

\begin{tabular}{lcc}
$\begin{array}{l}\text { Day of } \\
\text { life }\end{array}$ & & $\begin{array}{c}\text { Total bilirubin } \\
(\mu \mathrm{mol} / \mathrm{L})\end{array}$ \\
\hline 12 & & $126.5(\mathrm{H})$ \\
42 & & $119.5(\mathrm{H})$ \\
52 & & $83.9(\mathrm{H})$ \\
55 & & $96.8(\mathrm{H})$ \\
67 & & $39.9(\mathrm{H})$ \\
92 & & 10.3 \\
184 & 4.9 \\
\hline
\end{tabular}

\begin{tabular}{c}
$\begin{array}{c}\text { Direct bilirubin } \\
(\mu \mathrm{mol} / \mathrm{L})\end{array}$ \\
\hline $40.6(\mathrm{H})$ \\
$78.8(\mathrm{H})$ \\
$53.9(\mathrm{H})$ \\
$57.9(\mathrm{H})$ \\
$22.9(\mathrm{H})$ \\
- \\
- \\
\hline
\end{tabular}

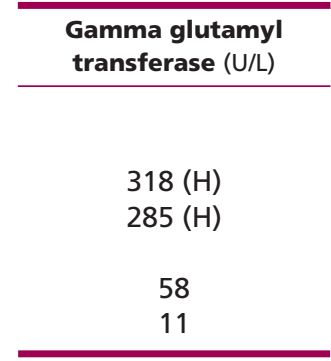
Alkaline phosphatase (U/L) Alanine amino-transferase (U/L)

$\mathrm{H}$, higher than normal range. 


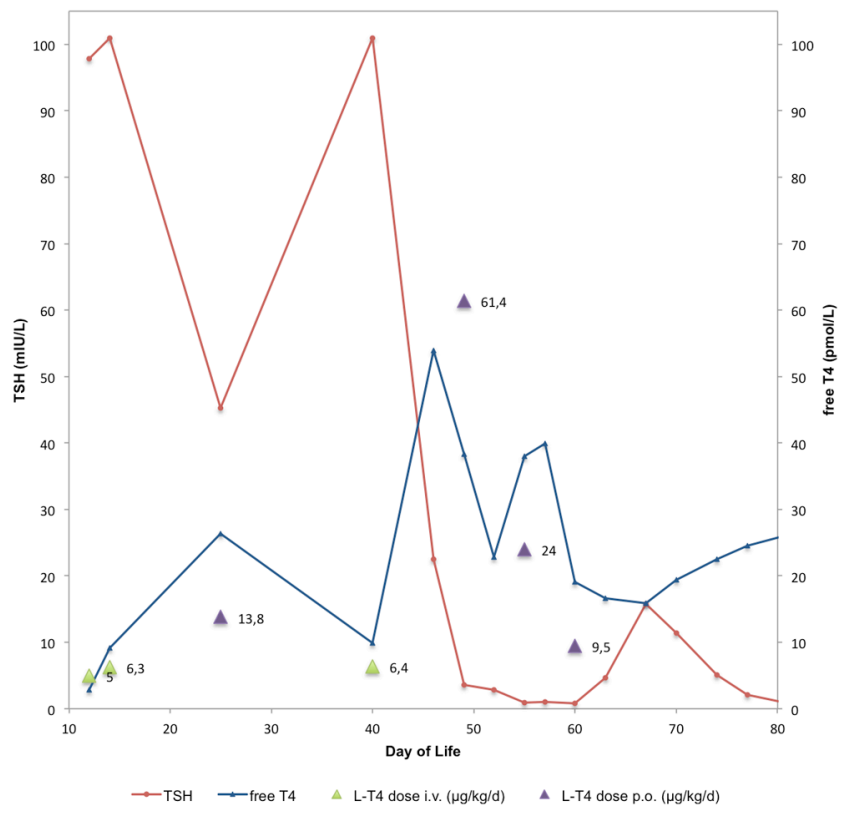

Figure 1

Changes in TSH and free T4 levels in the course of L-T4 treatment. The normal ranges for TSH (0.34-5.6IU/L) and free T4 (12-55 pmol/L in newborns and $8-18 \mathrm{pmol} / \mathrm{L}$ in children and adults) are indicated by shaded areas.

methods of alternative long-term L-T4 administrations were discussed in an attempt to avoid hospital-based intravenous treatment. Considering the large required injection volumes and limited research regarding intramuscular and subcutaneous LT4 administration forms, we decided to try a very high oral L-T4 dose instead. When the TSH had fully normalized (3.61 IU/L), L-T4 at $61.4 \mu \mathrm{g} / \mathrm{kg} /$ day $(\sim 500 \%$ of usual neonatal PO dose) was initiated, based on the assumption that $80 \%$ of L-T4 is absorbed in the jejunoileal area (3). TSH levels continuously decreased, and a gradual reduction of the oral L-T4 dose was possible (Fig. 1).

\section{Outcome and follow-up}

Euthyroidism was achieved at 4 months of age and the patient was well controlled on oral L-T4 at $7 \mu \mathrm{g} / \mathrm{kg} / \mathrm{day}$ at 9 months of age (usual dose for age). Pulmonary, gastrointestinal and neurological symptoms as well as cholestasis completely resolved. A thyroid ultrasound showed a normally placed thyroid gland.

\section{Discussion}

To our knowledge, this is the first case reporting successful high-dose oral LT-4 replacement in a neonate with $\mathrm{CH}$,
NEC and subsequent extensive ileal resection. The absorption of L-T4 after oral administration averages $62-82 \%$ and mainly occurs in the jejunum and ileum (5). It is known to be disrupted by a number of factors including food intake, malabsorptive disorders and drugs. In the presented case, transient malabsorption of enteral L-T4 was most likely caused by the subtotal resection of the ileum, which significantly reduced the intestinal surface for L-T4 absorption. Mucosal injuries secondary to NEC and the post-surgical state may have led to further decrease in absorption capacity. Patients with short bowel syndrome in the context of NEC seem more likely to regain enteral autonomy than patients with other underlying diseases (6). The neonatal intestinal tissue can adapt to partial loss of the small intestine by upregulation of nutrient absorption in the remaining bowel. Changes in crypt cell production rate, crypt depth and villus height enlarge the functional surface area in the small intestine, while the colon can additionally support absorption (7). Studies suggest that thyroid hormone stimulates this adaption process (8), emphasizing the importance of euthyroidism after intestinal surgery. Our patient appeared to have fully regained enteral autonomy after appropriate treatment with LT4.

Since not all patients seem to regain this autonomy following NEC (6) consideration of long-term alternatives to oral L-T4 administration may be necessary in neonates with $\mathrm{CH}$ and malabsorption. A few adult case studies have reported long-term use of L-T4 formulations other than oral or intravenous, including subcutaneous (9) and intramuscular administration (10). However, L-T4 injection volumes were high, limiting applicability to pediatric patients. Data on the use of alternative administration routes of L-T4 in newborns are lacking.

In our patient, despite immediate IV L-T4 supplementation, TSH rose rapidly. The chosen IV dose of $5 \mu \mathrm{g} / \mathrm{kg} /$ day corresponds to $30 \%$ and $50 \%$ of a usual PO starting dose of 15 and $10 \mu \mathrm{g} / \mathrm{kg} / \mathrm{day}$, respectively. Given the recommended conversion from PO to IV dosing typically ranges from 50 to $80 \%$, and given that $15 \mu \mathrm{g} /$ $\mathrm{kg} /$ day has been widely recognized as a superior starting dose due to improved neurocognitive outcomes (11), the starting dose chosen in our patient was relatively low. Following a dose increase to $6.3 \mu \mathrm{g} / \mathrm{kg} / \mathrm{day}(40 \%$ of $15 \mu \mathrm{g} / \mathrm{kg} /$ day and $62.5 \%$ of $10 \mu \mathrm{g} / \mathrm{kg} /$ day PO dosing), TSH decreased and eventually euthyroidism was safely achieved. Afterward, high-dose oral L-T4 in crushed tablet formulation was used to maintain euthyroidism. The starting oral L-T4 dose was determined based on the assumption, that approximately $80 \%$ of the intestinal 
surface for L-T4 absorption was resected. Alternatively to our solution, patients with short bowel syndrome may benefit from the use of other formulations of oral L-T4 such as soft gel or oral solution. Studies have shown that those formulations are less affected by $\mathrm{pH}$ changes and therefore may provide better absorption levels than the traditional tablets (12). Fallahi and coworkers reported 17 cases of hypothyroid adults after extensive bowel surgery (Roux-en-Y gastric bypass or biliary pancreatic diversion), who were successfully treated with liquid L-T4 in order to avoid its malabsorption (13). Several studies have confirmed the efficacy of the use of liquid formulations of L-T4 in newborns with congenital hypothyroidism in general $(14,15)$, but not in the context of bowel resection. Independently from the formulation used, close TSH monitoring and frequent dose adjustment are necessary to avoid periods of hypothyroidism and hyperthyroidism.

In the course of her admission, our patient developed cholestasis. Hypothyroidism is known to cause cholestasis (16), but at the same time, cholestasis leads to malabsorption of lipophilic substances and therefore may have additionally impaired L-T4 absorption (17).

In conclusion, congenital hypothyroidism can cause severe complications, which may interfere with the treatment of the underlying disease. Bowel surgery in the context of NEC can lead to malabsorption of orally administered L-T4. Normal absorption levels may be regained later due to adaption of the neonatal intestines. However, euthyroidism needs to be restored rapidly to minimize the risk of neurological consequences and to enhance the intestinal adaption process. This is one of the few case reports describing the efficacy and safety of intravenous L-T4 administration in providing rapid normalization of free T4 and TSH in infants with malabsorption after NEC. High-dose enteral L-T4 should be considered once euthyroidism is established, and the initial dose can be determined based on the estimated degree of malabsorption. Since the absorption levels and degree of intestinal adaption may vary widely, closer thyroid function monitoring than usual and immediate therapy adjustment are necessary.

\section{Declaration of interest}

The authors declare that there is no conflict of interest that could be perceived as prejudicing the impartiality of the research reported.

\section{Funding}

This research did not receive any specific grant from any funding agency in the public, commercial or not-for-profit sector.

\section{Patient consent}

Informed consent has been obtained from the patient's guardians.

\section{Author contribution statement}

All the authors contributed to the clinical management of this patient and to the writing and editing of this case report. All the authors accepted responsibility for the entire content of this submitted manuscript and approved submission.

\section{References}

1 Grüters A \& Krude H. Update on the management of congenital hypothyroidism. Hormone Research 200768 (Supplement 5) 107-111. (https://doi.org/10.1159/000110591)

2 Amer T, David R \& Oberfield S. Necrotizing enterocolitis and hypothyroidism in a newborn infant: treatment with intravenous L-thyroxine. American Journal of Perinatology 199411 30-32. (https:// doi.org/10.1055/s-2007-994530)

3 Bolisetty S, Lui K, Oei J \& Wojtulewicz J. A regional study of underlying congenital diseases in term neonates with necrotizing enterocolitis. Acta Paediatrica 200089 1226-1230. (https://doi. org/10.1111/j.1651-2227.2000.tb00740.x)

4 Liwanpo L \& Hershman JM. Conditions and drugs interfering with thyroxine absorption. Best Practice and Research: Clinical Endocrinology and Metabolism 200923 781-792. (https://doi.org/10.1016/j. beem.2009.06.006)

5 Hays MT. Localization of human thyroxine absorption. Thyroid 1991 1 241-248. (https://doi.org/10.1089/thy.1991.1.241)

6 Sparks EA, Khan FA, Fisher JG, Fullerton BD, Hall A, Raphael BP, Duggan C, Modi BP \& Jaksic T. Necrotizing enterocolitis is associated with earlier achievement of enteral autonomy in children with short bowel syndrome. Journal of Pediatric Surgery 201651 92-95. (https:// doi.org/10.1016/j.jpedsurg.2015.10.023)

7 Thompson JS. Surgical rehabilitation of intestine in short bowel syndrome. Surgery 2004135 465-470. (https://doi.org/10.1016/j. surg.2003.12.004)

8 Yuksel O, Tatlicioglu E, Poyraz A, Sahin T, Pasaoglu H, Ekinci O, Salman B \& Yilmaz U. Effects of thyroid hormone on the adaption in short Bowel syndrome. Journal of Surgical Research 2009155 116-124. (https://doi.org/10.1016/j.jss.2008.07.036)

9 Groener JB, Lehnhoff D, Piel D, Nawroth PP, Schanz J \& Rudofsky G. Subcutaneous application of levothyroxine as successful treatment option in a patient with malabsorption. American Journal of Case Reports 201314 48-51. (https://doi. org/10.12659/AJCR.883788)

10 Nobre EL, Jorge Z, Anselmo J, Lopes C, César R, Santos V \& Castro JJ. A rare case of malabsorption of thyroid hormones. Acta Médica Portuguesa 200417 487-491.

11 Selva KA, Harper A, Downs A, Blasco PA \& Lafranchi SH. Neurodevelopmental outcomes in congenital hypothyroidism: comparison of initial T4 dose and time to reach target T4 and TSH. Journal of Pediatrics 2005147 775-780. (https://doi.org/10.1016/j. jpeds.2005.07.024)

12 Vita R, Fallahi P, Alessandro Antonelli A \& Benvenga S. The administration of L-thyroxine as soft gel capsule or liquid solution. Expert Opinion on Drug Delivery 201411 1103-1111. (https://doi.org/ 10.1517/17425247.2014.918101)

13 Fallahi P, Ferrari SM, Camastra S, Politti U, Ruffilli I, Vita R, Navarra G, Benvenga S \& Antonelli A. TSH normalization in bariatric surgery patients after the switch from L-thyroxine in tablet to an oral liquid formulation. Obesity Surgery 201727 78-82. (https://doi. org/10.1007/s11695-016-2247-4) 
14 Peroni E, Vigone MC, Mora S, Bassi LA, Pozzi C, Passoni A \& Weber G. Congenital hypothyroidism treatment in infants: a comparative study between liquid and tablet formulations of levothyroxine. Hormone Research in Paediatrics 201481 50-54. (https://doi.org/10.1159/000356047)

15 Cassio A, Monti S, Rizzello A, Bettocchi I, Baronio F, D’Addabbo G, Bal MO \& Balsamo A. Comparison between liquid and tablet formulations of levothyroxine in the initial treatment of congenital hypothyroidism. Journal of Pediatrics 2013162 1264.e1-2-1269.e1-2. (https://doi.org/10.1016/j.jpeds.2012.11.070)

16 Laukkarinen J, Sand J, Saaristo R, Salmi J, Turjanmaa V, Vehkalahti P \& Nordback I. Is bile flow reduced in patients with hypothyroidism? Surgery 2003133 288-293. (https://doi.org/10.1067/msy.2003.77)

17 Higuchi A \& Hasegawa Y. Dose adjustments of hydrocortisone and L-thyroxine in hypopituitarism associated with cholestasis. Clinical Pediatric Endocrinology 200615 93-96. (https://doi.org/10.1297/cpe.15.93)

Received in final form 14 January 2018

Accepted 26 January 2018 